\title{
Bank Capital for Operational Risk: A Tale of Fragility and Instability
}

\section{Citation}

Mark Ames, Til Schuermann \& Hal S. Scott, Bank Capital for Operational Risk: A Tale of Fragility and Instability (Harvard John M. Olin Discussion Paper Series Discussion Paper No. 763, Feb. 2014, 8 J. Risk Mgmt. Fin. Inst. 227 (2015)).

\section{Published Version}

http://www.law.harvard.edu/programs/olin_center/papers/pdf/Scott_763.pdf

\section{Permanent link}

http://nrs.harvard.edu/urn-3:HUL.InstRepos:20207070

\section{Terms of Use}

This article was downloaded from Harvard University's DASH repository, and is made available under the terms and conditions applicable to Other Posted Material, as set forth at http:// nrs.harvard.edu/urn-3:HUL.InstRepos:dash.current.terms-of-use\#LAA

\section{Share Your Story}

The Harvard community has made this article openly available.

Please share how this access benefits you. Submit a story.

Accessibility 


\section{HARVARD}

JOHN M. OLIN CENTER FOR LAW, ECONOMICS, AND BUSINESS

BANK CAPITAL FOR OPERATIONAL RISK:

A TALE OF FRAGILITY AND INSTABILITY

Mark Ames

Til Schuermann

Hal S. Scott

Discussion Paper No. 763

$02 / 2014$

Harvard Law School

Cambridge, MA 02138

This paper can be downloaded without charge from:

The Harvard John M. Olin Discussion Paper Series: http://www.law.harvard.edu/programs/olin_center/

The Social Science Research Network Electronic Paper Collection:

$\underline{\text { http://ssrn.com/abstract=2396046 }}$ 


\title{
Bank Capital for Operational Risk: A Tale of Fragility and Instability
}

\author{
Mark Ames \\ Oliver Wyman
}

\author{
Til Schuermann* \\ Oliver Wyman and \\ Wharton Financial \\ Institutions Center
}

Hal S. Scott

Harvard Law School

February 10, 2014

\section{DRAFT}

\begin{abstract}
Operational risk is fundamentally different from all other risks taken on by a bank. It is embedded in every activity and product of an institution, and in contrast to the conventional financial risks (e.g. market, credit) is harder to measure and model, and not straight forwardly eliminated through simple adjustments like selling off a position. Operational risk tends to be about 9-13\% of the total risk pie, though growing rapidly since the 2008-09 crisis. It tends to be more fat-tailed than other risks, and the data are poorer. As a result, models are fragile - small changes in the data have dramatic impacts on modeled output - and thus required operational risk capital is unstable. Yet the regulatory capital regime is, surprisingly, more rigidly model focused for this risk than for any other, at least in the U.S. We are especially concerned with the absence of incentives to invest in and improve business control processes through the granting of regulatory capital relief. We make four, not mutually exclusive policy suggestions. First, address model fragility through anchoring of key model parameters, yet allow each bank to scale capital to their data using robust methodologies. Second, relax the current tight linkage between statistical model output and required regulatory capital, incentivizing prudent risk management through joint use of scenarios and control factors in addition to data-based statistical models in setting regulatory capital. Third, provide allowance for real risk transfer through an insurance credit to capital, encouraging more effective risk sharing through future product innovation. Fourth, expand upon the standard taxonomy of event type and business line to include additional explanatory variables (such as product type, flags for litigated events, etc.) that would allow more effective interbank sharing and learning from experience. Until our understanding of operational risks increases, required regulatory capital should be based on methodologies that are simpler, more standardized, more stable and more robust.
\end{abstract}

\footnotetext{
*(Corresponding author: til.schuermann@oliverwyman.com). Professor Scott's participation in this project was supported under his general consulting relationship with State Street Corporation. We would like to thank Eduardo Canabarro, Misha Dobrolioubov, Ramy Farha, John Jordan, Andy Kuritzkes and Daniel Mikkelsen for helpful comments and discussion. All remaining errors are ours, of course.
} 


\section{Introduction}

On May 16, 2012, Thomas Curry, the Comptroller of the Currency (head of the OCC), said in a speech $^{1}$ that bank supervisors are seeing "operational risk eclipse credit risk as a safety and soundness challenge." This represents a real departure from the past when concern was primarily focused on credit and market risk. A major component of operational risk is legal liability, and the recent financial crisis, a credit crisis par excellence, has been followed by wave after wave of legal settlements from incidents related to the crisis. Consider the $\$ 25$ billion settlement between the states and five large bank mortgage servicers (Ally, BofA, Citi, JPM, Wells), or, more recently, the LIBOR bid rigging penalties which have so far totaled $\$ 5.8$ billion.

Meanwhile, the use of models to steer a bank has both broadened (annual stress testing is now required by banks as small as $\$ 10 \mathrm{bn}$ in size) and deepened (within that stress testing, even the budgeting process is increasingly tied to macroeconomic variables). As banks have learned to better measure, model and manage risk, regulators too have come to rely on these models.

Under the Basel II Accord, three approaches are set forth for the determination of regulatory capital for operational risk. The most simple, the Basic Indicator Approach, applies a single $15 \%$ factor to average annual gross income - a very crude capital requirement by most any standard. Next in line is the Standardized Approach in which different percentages of income are applied across a set of standardized business lines. While this differentiated approach may come closer to achieving a more accurate reflection of an institution's risk, the highest expectations are put on Basel's AMA or Advanced Measurement Approach under which capital is determined by sophisticated internal models. This is the approach U.S. regulators (but not Basel itself) requires for large banks. However, relative to other risk types, operational risk is very difficult to accurately measure. Pertinent data are sparse and models of operational risk tend to be extremely sensitive and fragile to anomalies common in incoming data. Ironically, these internal models, fully intended to help manage risk, have actually created a significant new uncertainty for banks. ${ }^{2}$

The typical risk taxonomy that organizes bank capital requirements includes credit, market and operational risk, and regulatory capital requirements under Basel II follow that taxonomy. Often the list of risks is longer: it may separately include other risks, interest rate, FX, settlement, counterparty, legal, reputational, liquidity, and so on. But most of these risks can be readily subsumed into one of the big three risk types (interest rate and FX into market risk, settlement and counterparty into credit, legal into

\footnotetext{
${ }^{1}$ http://www.occ.gov/news-issuances/speeches/2012/pub-speech-2012-77.pdf

2 Model risk is itself a type of operational risk, classified under Clients Products and Business Practices (see Error! Reference source not found. for details). However, regulatory risk is not part of the Basel event taxonomy.
} 
operational, and so on). Other risks, for example business and reputational, while certainly not ignored by banks, are typically not explicitly capitalized under either regulatory requirements or internal capital frameworks. The measurement of the financial risk (market and credit) is particularly well studied, and there are very well established practices for managing these risks. For example, it is straight forward to eliminate market risk by closing out the position, or credit risk by selling the exposure. Indeed exposure, even for a derivatives position, is neither ambiguous nor unbounded. This is not the case for operational risk.

As we describe in more detail later, Basel II disclosure from non-US banks show that operational risk has been growing from about $9 \%$ in 2008 to $13 \%$ in $2012 .{ }^{3}$ Given the vast liability regime differences between the U.S. and the rest of the world, we would expect Basel II/III disclosures from U.S. banks to be beyond the high range for non-U.S. banks.

Operational risk is fundamentally different from all other risk types. ${ }^{4}$ To again quote Curry (2012), "The risk of operational failure is embedded in every activity and product of an institution." Importantly, there is no natural way to cleanly eliminate operational risk. The settlement of a lawsuit does not eliminate risk; an operational loss merely provides some evidence of how large the risk has been, and so arguably how large it could be in the future. How much damage could a rogue trader wreak? Every new incident sheds light on this question. But should each such incident necessarily point to ever higher levels of capital? After each significant loss event, there is an inevitable push to improve risk management, to close an observable gap, not just at the offending bank but across the industry. Yet if a new largest loss has been "observed" in data, recalibrated models tend to generate larger numbers resulting in greater required capital, regardless of mitigating actions put in place as a result of the event. As many institution's models are directly tied to industry loss experience, this has effectively led to a one-way capital regime, always up, that offers little in the way of positive, prospective incentives; plenty of stick, not much carrot.

In this paper we provide a non-technical overview of the core issues confronting the industry on operational risk and its regulatory treatment today. In the face of an unobservable, arguably unknowable exposure, we only learn about the nature of operational risk through new events and the damage they cause. How do we then balance our proactive response with improved risk management processes against the demand of the models for more capital? Can operational risk capital ever go

\footnotetext{
${ }^{3}$ Kuritzkes and Schuermann (2010) report a range of 10-15\% attributable to operational risk, as taken from bankinternal economic capital models, albeit before the financial crisis.

${ }^{4}$ When aggregating across risk types in economic (internal) capital models, the result tends to be highly sensitive to the characterization of operational risk. See Rosenberg and Schuermann (2006).
} 
down? Any regulatory capital regime designed to address operational risk must come to grips with these questions.

We have four broad policy suggestions:

1. Address the widely reported problem of model fragility which results in very unstable capital numbers. Possible avenues for solutions include

a. Regulators could specify key parameters (i.e., shape) for loss severity, leaving banks to calibrate scale assumptions to their data using robust methodologies. Regulators are well equipped to do this by taking advantage of their privileged position of having access to data and analysis across the range of regulated banks, e.g. the Fed through the U.S. CCAR program.

b. Similar to the Basel approach to calculating market risk capital, we suggest to calculate the capital measure at a lower percentile (say 95\%) and scale up via a multiplier, determined by regulators, to obtain the confidence level desired (currently set at $99.9 \%$ ).

c. Reconsider Basel's Standardized Approach, and make that approach, as further refined, optionally available to large banks (as Basel itself permits).

2. Relax the current tight linkage between statistical model output and required regulatory capital, ideally encouraging better controls and incentivizing more effective risk management. This could follow from allowing greater influence (up and down) on capital requirements through the use of scenarios and BEICFs. ${ }^{5}$

3. Encourage banks to further explore risk transfer as an option for effective loss mitigation through an insurance credit to capital. Positive developments here could well result in innovation of coverage, terms and conditions that would make insurance even more effective as surrogate capital supporting operational risk.

4. Suggest/require that institutions expand data capture beyond the Basel event type and business line classifications to allow further investigation into key explanatory factors. Examples could include product, flags for litigated events, relational links to insurance policy and coverage, etc. Only through systematic capture of more detailed factors can insights be drawn across institutions, reducing the uncertainty around effective use of external loss data. The Basel taxonomy was developed over a decade ago when the discipline was still in its infancy, and was never ideally designed for risk and capital measurement. Finally given its importance, special attention should be given to assigning a special category to liability risk.

\footnotetext{
${ }^{5}$ Business Environment and Internal Control Factors: one of the four information types allowed by the Basel rules; details below.
} 
In section 2 we start with a quick introduction of definitions and the regulatory taxonomy of operational risk event types. We move on to examining the raw ingredients, the data, both internal and external. Section 3 moves from data to modeling where we provide a nontechnical overview of how the industry approaches the modeling problem, as well as the important and difficult problem of taking the model output and translating it into required capital. Here we also consider the problem of measuring the impact of risk mitigants, such as improvements in processes and control, as well as risk transfer through insurance. Section 4 revisits the policy problem and provides some concluding remarks.

\section{Definition, taxonomy and data}

The Basel Committee has defined operational risk as "the risk of loss resulting from inadequate or failed internal processes, people and systems or from external events." This regulatory definition includes legal risk but excludes strategic and reputational risk. ${ }^{6}$ Operational risk is subdivided into seven event types, listed in Error! Reference source not found.. Many of the largest recent mortgage litigation losses have been categorized into the Clients, Products \& Business Practices (CPBP) risk type. A second dimension of the Basel data taxonomy is business line, of which there are eight major defined lines of business, listed in Error! Reference source not found.. As a consequence of this taxonomy, granular modeling of loss tends to be done across a defined combination of event types and business lines called a unit of measure (UOM). In deciding on UOMs, banks tend to stay within this Basel taxonomy, typically starting with the seven event types and subdividing by business line within event type where the risk is deemed different and where credible data exist to support the business line subdivision.

The taxonomy of event types was designed to facilitate risk management by looking to the causes and thus the prevention of events. However, it is important to recognize the ambiguity this taxonomy creates. Most events do not occur in isolation but are the result of (or enabled by) multiple causes. In assigning a loss to UOM, practitioners must identify a "primary" cause. For example, is LIBOR bid rigging an internal fraud or a bad business practice? There are also operational events that cross multiple business lines, for example a property loss. But models are not "smart"; implicit in the modelling of operational risk is the assumption that classification of data into homogeneous UOMs is correct and that each new event unambiguously belongs to one and only one unit of measure. But as the assignment of a new event to UOM can often be subjective, the assignment itself introduces uncertainty with regard to how a quantitative model will respond. A new large event landing in one UOM may have no discernible

\footnotetext{
${ }^{6}$ BCBS (2006), §644.
} 
effect on capital, while in another it could cause a huge increase, in effect "blowing up" the model. The presumption that the event taxonomy is correct is central to the modeling process.

The data taxonomy imposed by the Basel Committee was developed in the late 1990s when operational risk data gathering and modeling was still in its infancy. All taxonomies seek to classify items into progressively homogenous groups or types, and this taxonomy is no different. But we note that this is a difficult challenge; one only need look at that taxonomy of coverages prevalent in the insurance industry to see the challenges associated with crafting an unambiguous event taxonomy. But as it has been over a decade now since the introduction of the Basel taxonomy for operational events, accompanied by significant and broad-based data gathering efforts in the industry, it may well be time to revisit this taxonomy to see if it can be improved or expanded upon. Here the goal should be to track additional information about events, to allow more homogeneous grouping, more appropriate for accurate measurement, and ultimately facilitate more effective risk management.

The case for revisiting these categories is particularly important with respect to bank legal liability, largely captured by CPBP. Although there is no publicly available data indicating what percentage CPBP accounts for in terms of overall capital held for operational risk, we suspect that CBPB is the dominant driver of overall operational risk capital; it has certainly been a most important area of concern since the 2008 financial crisis. In 2012 and 2013, financial institutions respectively incurred \$31.3 billion and \$43.4 billion in regulatory fines and penalties. ${ }^{7}$ In addition, in 2012, public companies settled \$2.9 billion in private securities class action lawsuits (which were as high as $\$ 19.7$ billion in 2006). ${ }^{8}$ In 2012, one-third of these settlements were with financial firms. For the purpose of capital assessment, it would seem to make sense to focus more on this particular event type, and look toward systematically improving the data to better differentiate between products, flagging litigated events, etc.

Basel II requires banks to incorporate four types of information into their models: internal loss data, external loss data, scenarios, and business environment and internal control factors (BEICFs). The reason for the inclusion of each type of information is easy to understand. Internal data are the losses that an institution has suffered directly and so are most directly relevant to the modelling. Institutions should also learn from other's losses and so external data are pertinent. Loss scenarios are those potential events that can be identified through expert judgment and so should be reflected in a model's output. Finally, the risk control environment obviously impacts loss outcomes. However, each element comes with its own promise and challenge.

\footnotetext{
${ }^{7}$ Committee on Capital Markets Regulation (2013): http://capmktsreg.org/2013/10/committee-releases-quarterlyfinancial-penalties-data/

${ }^{8}$ Ellen Ryan and Laura Simmons, Cornerstone, Securities Class Action Settlements (2006).
} 
Banks generally collect internal data based on a materiality threshold for recording an event. That threshold can be as low as zero (though in practice it is much higher), but capturing and processing this data is costly, so one must question the value of collecting very small losses. How far down to go tends to depend on the business profile; e.g., a credit card issuer may well want to have a lower thresholdsince a material risk includes the accumulation of small-loss external fraud events-rather than a bank whose risk is dominated by significant trading operations. It is worth noting that the very act of systematically capturing data, even for apparently modest amounts, can help to cement a culture of operational risk awareness. ${ }^{9}$

A variety of external data are available, and these can be broadly classified into two categories: public and industry consortium. Public data are gathered from sources such as newspapers and journals, occasionally a very sensational loss will show up as note to a firm's financial statements. An example of this kind is the SAS OpRisk Global Data; while SAS seeks to capture all losses in excess of US\$100,000, there is a fundamental limitation as only those losses that are revealed to the public domain can be captured - and few banks rush to publicize bad news. Public data have been collected since the late 1990s, capturing events from even back into the 1970s. In the early days of operational risk modeling, these public data were especially critical as banks' efforts toward internal data collection were just getting off the ground. Events revealed to the public eye typically come with a story line, descriptive information that potentially allows modelers to assess relevance. It is generally assumed that the larger and more notorious is an event, the greater its likelihood of finding its way into the public domain. However, the capture of such data through public sources is far from complete, making it statistically difficult to use these data in modelling.

From a modelling perspective, the introduction of data-sharing industry consortia has represented a large improvement, primarily as the collected consortium data may be deemed complete. ORX is currently the largest of these data consortia, having been in operation since 2002, about the time that the Basel Committee established the 7-event type operational risk taxonomy. As of this writing, ORX has membership of 65 firms representing 20 countries. ORX requires that all losses greater than $€ 20,000$ be reported from their members and currently maintains a database of some 350,000 events. Each loss is classified by the member bank into a particular Basel event type and business lines. ORX receives the data from participating institutions, anonymizes the submissions and shares the compiled database back to its membership. But at this point any story line associated with events is lost. Individual losses are

\footnotetext{
${ }^{9}$ To be sure, the issue with internal loss data is not so much what the threshold should be, but whether the data are sufficient. For low-frequency UOMs, we do not know, based on internal data, whether a bank has been good (or bad) or lucky (or unlucky).
} 
identified only by geography, business line and event type; to protect confidentiality, specifically the identity of the institution which suffered the loss, no further detail is provided. Consortium data may be complete, but they are intentionally not transparent.

Even in the absence of Basel II, data credibility would suggest that external data be incorporated into models. It's the low frequency high-severity events that drive capital, and such events are generally rare. For all but the largest banks, internal loss data (thankfully) "suffers" from a lack of statistical credibility because such large losses are infrequent. As a practical matter then, the decision whether to incorporate external data into the modeling mix is generally made on a UOM-by-UOM basis; not surprisingly, those UOMs with very few, very severe losses (as for example as CPBP) are precisely those with least-credible internal data and so most in need of augmentation with external experience. In this way, many/most banks' models are "exposed" to the industry's largest losses. A large loss for one institution thus transmits to increased capital requirements for other institutions.

Clearly then, what may be data enrichment for one bank can be viewed as data infection by another. Any new operational loss event reported by a given bank will affect all other bank's models built on such data. Currently, with the prevalence of some very large litigation losses following the financial crisis, this externality has become an acute problem. As an example, banks that did not participate in LIBOR rate setting could well have their capital model results driven by the penalties (and civil liability) associated with LIBOR bid rigging. As these events are not clearly labeled as such, it becomes very difficult for banks not involved in rate setting to argue their removal. Thus, many banks are feeling individually required to pay with their capital for the most egregious sins of the industry. Indeed this variation of the well-known commons problem is an important consideration in any policy design, a topic we return to later.

So a reasonable suggestion might be for banks to simply assess the external data for relevance to their business model. This turns out to be more difficult than one might imagine. Before ORX came into being, the only external data available were the public data. As mentioned above, a limited amount of descriptive information is typically released with public disclosure, but it is understandable that a bank having suffered a large loss is not generally inclined to be any more detailed than is required. Consequently, while it is sometimes possible to filter these public data for relevance, it is often difficult. The situation grows worse with the consortium data. As most banks shifted to the consortium data to avoid the reporting bias inherent in the public data, they gave up even the limited descriptions that allowed such filtering. As described above, users then are left with simple event type and business line assignments, not nearly the level of detail required to make a compelling argument for excluding a given 
observation. A bank is left little information content with which to argue that a new large external loss, classified to their business line - that blows up their model - is not relevant to them.

The most commonly used and regulatory accepted filters then are simply geography and business line. The anonymity of reported events that consortia like ORX go through makes it difficult/impossible to design more granular filters because critical information like product or service is omitted. A bank may often find itself in the awkward position where data have passed the business line and geography filters, yet they suspect an individual event may be quite unrelated to their particular operation and so still they would wish to exclude it. Without being able to come up with a descriptive argument for exclusion, they may try to construct a statistical argument for exclusion; though these arguments have been met by regulators with high scepticism and limited success. Coupled with the subjectivity of classification described above, banks have little assurance that even those external losses that fall outside their product mix will not wreak havoc on their model, and their capital requirements.

The two remaining regulatory-required inputs are scenario analysis and business environment and internal control factors (BEICFs); each too comes with its own promise and pitfalls. Certainly the intent of scenarios is to allow experts to look for possible loss outcomes, both different and larger than hitherto observed, expanding data beyond the experienced events found in the loss databases. Scenarios are the result of creative judgment, losses that have not occurred historically but are possible within a firm's business model. Scenario development has become an elaborate and highly formalized process unto itself, in large part to avoid a number of different biases that might otherwise corrupt a consensus-driven expert opinion. Scenario analysis has proven to be a great tool for identifying risk management opportunities: a group of experts, coming together to discuss a particular set of scenarios will often hit upon new insights on how to better control risk. Not dissimilar to what happens naturally in the aftermath of a large loss, these discussions around potential future losses will tend to raise risk awareness and offer opportunities to improve the control environment.

BEICFs meanwhile will ideally reflect a very broad set of mechanisms, including compliance systems, checks and reconciliations, system access controls, physical access controls (e.g. access cards), sales controls (e.g. recorded conversations), employee controls (e.g. pre-employment screening), and others. BEICFs are in theory derived or compiled from a measured assessment of the bank's internal control environment. However, there is no standardization as to what constitutes a good or a bad control environment. Also, it is difficult to draw certain conclusions on the basis of the absence of loss data.

Scenarios and BEICFs may be used as direct inputs into an AMA regulatory capital model or as indirect inputs, i.e. as modifiers or checks. But as these two inputs tend to be subjective, i.e., reliant on 
the judgment of a firm's internal experts and processes, regulators in the US have shown extreme caution in using them and have revealed a strong preference that models be anchored firmly to the arguably more objective internal and external loss data. This view is not unreasonable, given the bias that might creep into judgment when capital implications are considered. But as a result, scenarios and BEICFs appear destined to remain a regulatory stick rather than a carrot. Unlike losses that have happened in the past, scenarios and BEICFs are forward looking and so would be the first model inputs to reflect an improved control environment. But potentially "rewarding" the bank with a lower regulatory capital charge, their subjectivity opens them to gaming and so are suspect.

Because of the concern that a perverse incentive might bias scenarios downward, and assessment of the control environment upward, scenarios and BEICFs are typically relegated to use strictly outside of or supplementary to the capital model itself. It is broadly perceived in the industry that US regulators will only allow these inputs to increase, not reduce required capital. But not giving credit for capped scenarios or improving BEICFs -incentivizing the reduction of risk through enhanced controls -is a significant gap in the current regulatory approach to operational risk. Proper exercise of supervisory judgment should not give way to over reliance on what may be objective data, but data that cannot predict the future accurately. Regulators should subject scenarios and BEICFs to a thorough review and where appropriate permit them to reduce required capital.

\section{From data to models to capital}

In the United States, larger banks are required to develop their own internal models for operational risk. These banks are often referred to as AMA banks, indicating that each has adopted one of the Advanced Measurement Approaches to the estimation of minimum required capital for operational risk. ${ }^{10}$ By far the dominant approach in the industry is the Loss Distribution Approach (LDA) in which statistical distributions are used to describe the frequency and the severity of events within each UOM. ${ }^{11}$ These statistical assumptions are typically used in simulations to generate many trials, or simulated years, to describe the range of possible outcomes. Some trials will have more or fewer events; some events will be smaller or larger. With correlations assumed between UOMs for aggregation, taken together the trials are meant to describe proportionately the full distribution of possible annual loss.

Underlying this modeling approach are certain statistical assumptions, for example the independence of one event from the next, as well as independence of the frequency of occurrence and

\footnotetext{
${ }^{10}$ See also US regulatory guidance SR 11-08: http://www.federalreserve.gov/bankinforeg/srletters/sr1108a1.pdf

${ }^{11}$ See Sekeris (2012) for a good discussion.
} 
the severity of a given event. There are reasons to believe these assumptions may be quite unrealistic. A good example is the set of uncertain legal claims arising from one practice, namely poor mortgage underwriting before the crisis. This event type, which is classified under CPBP, tends to dominate in importance operational risk databases. ${ }^{12}$ These events are neither independent from one another, nor is it true that their frequency is not linked to severity. Moreover, the independence assumptions are overtly questioned in the US supervisory stress testing process, the Comprehensive Capital Analysis and Review (CCAR), where banks are asked to model operational risk as being driven by macroeconomic variables such as unemployment or stock market volatility. ${ }^{13}$

How to account for frequency in models is largely uncontroversial, but important. By far the most common frequency assumption is the single-parameter Poisson model which simply requires an estimate of the average rate of occurrence in a given time increment. ${ }^{14} \mathrm{~A}$ perhaps under-examined modeling element is the degree to which one needs to account for event clustering since the standard approach assumes event independence. Time windows for data present another challenge; risk is not static. In particular, timelines for frequency can show the result of improved controls just as easily as changing external environment. Sensibly factoring trends in loss event arrivals has also been given short attention, as this too would reflect in capital charges in either direction, further enforcing incentives toward prudent management.

The choice of severity distribution is far more controversial, and problematic. To understand why, consider that the capital consumed by operational risk, especially in severe scenarios, is generally dominated by a single large event. Unlike credit risk, where a portfolio of loans exposed to a common cause, say a downturn in the economy, may result in many individual loan losses that only in aggregate produce a bad result, correlation does not generally drive operational risk. While certainly possible, it is hard to imagine why a capital-draining external fraud, devastating property damage, or a significant rogue trader event should naturally occur together. Of course there are examples of dependent events (the clustering of legal claims from the subprime crisis is an obvious example), but this is more likely the case within, rather than across, event types and UOMs. The reality here is that operational risk capital is effectively sized, not to cover many occurrences, but the single worst case.

\footnotetext{
${ }^{12}$ An excellent discussion of this operational risk loss clustering is given in Chernobai and Yildirim (2008) presciently written before the financial crisis.

${ }^{13}$ There is some supporting evidence of pro-cyclical operational risk; see Chernobai, Jorion and Yu (2011) and Moosa (2011).

${ }^{14}$ When the data exhibits over-dispersion (the variance far exceed the average rate of occurrence), the twoparameter negative binomial distribution is a common alternative.
} 
For AMA banks, regulatory capital is obtained through a value-at-risk (VaR) approach and is defined as the $99.9 \%$ or 1 -in-1000 year outcome - which gives some sense of the degree of extrapolation required in operational risk modeling when many institutions now have no more than 10 or 15 years of data. The key means of extrapolation comes from the severity assumption; as operational risk is characterized by highly skewed and extreme outcomes, the assumed severity distributions must also be highly skewed and allow for extreme outcomes. The problem is that such distributions also tend to be extremely sensitive to the sparse data used for parameter estimation. That is, the same properties required for a model to simulate extreme events imply a huge sensitivity to extreme events in real data, notoriously the largest event in a dataset. Individual large events tend to drive parameters, determining just how fat the modeled severity "tail" will be. ${ }^{15}$

Quite importantly, in the U.S. (but less so in Europe) models are generally hard-wired to data and allow for few if any expert overrides or detailed application of judgment; again for fear of gaming, subjectivity in all areas including parameter estimation is deeply frowned upon by the regulatory community. As a result, operational risk models are inherently fragile and highly sensitive to new data arrivals, ironically by design. That model outputs can be highly volatile period-to-period is a reality. It has been highlighted in a number of recent papers and is a focal point of much current research. ${ }^{16}$ However, the regulators' acceptance of any proposed solution remains uncertain if it comes with a trade-off of less automatic increases of capital tied to large loss experience in the industry.

To illustrate this fragility problem, we consider a disguised example from a U.S. AMA bank for a particular UOM that is modelled with the common lognormal distribution. The statistical algorithm seeks to find the best "value" of the two relevant parameters: "mu" which broadly describes the location of the distribution (where, on average, severities fall), and the more important shape parameter "sigma." As sigma goes up, the distribution's extreme tail grows fatter, allowing greater probability for extremely large events. Larger events imply need for more capital.

Figure 1 shows what the algorithm must contend with. Finding the best parameter values is like climbing a probability hill: you want to get to the top, meaning you want to find that unique pair of parameters (mu, sigma) that best fits the data. When the model works well, there is a single sharp peak in the landscape, meaning there is clearly one version of the model that best fits the data. However, the contours in Figure 1 show the top of that hill resembles a rather long plateau. Parameter pairs along the ridge share very similar elevation and are statistically indistinguishable, meaning that there are many

\footnotetext{
${ }^{16}$ See for example Opdyke and Cavallo (2012)
} 
models that fit the data very nearly equally well. Applied naively to determine capital, the model suggests it is equally likely that required capital should be $\$ 500$ million, $\$ 1$ billion or $\$ 5$ billion. This is not an unrealistic example as even small variations in data can make the difference; it is all too common for practitioners of operational risk modeling.

Figure 1: Flat likelihood surface produces uncertainty around parameters and capital implications ${ }^{17}$

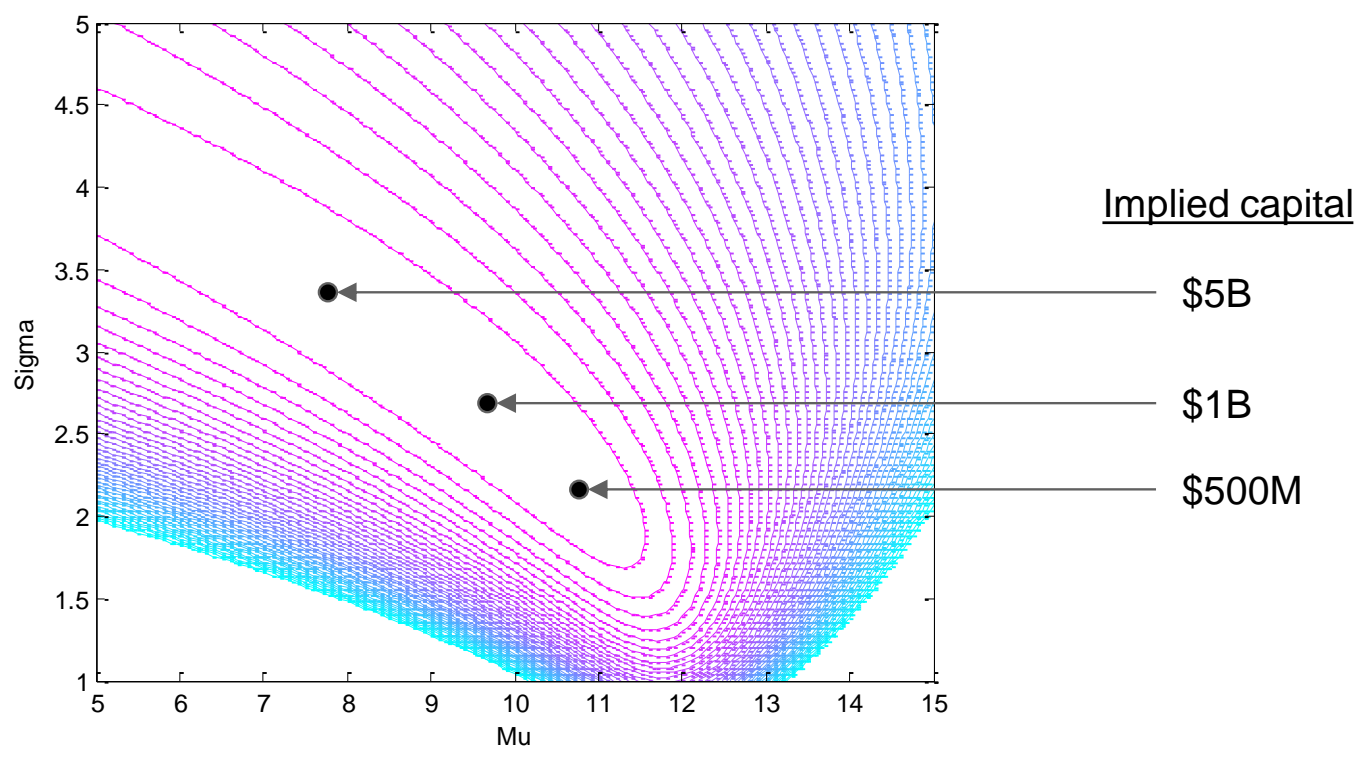

Unsurprisingly, it turns out too that the largest events in a loss dataset will tend to dominate the estimation. This presents a real problem for the modeler - and the regulator. Statistical models are geared to find what is most likely, to find the signal and filter out the noise. Because unusually extreme data points tend to impact the statistical model disproportionately, modelers routinely clean the data by removing outliers. But in operational risk, the "outliers" may be the most informative. And therein lies the dilemma: the inclusion of extreme observations results in very unstable and fragile models; yet techniques that might stabilize such models, for example methods from robust statistics, will tend to mute the impact of the observations that may be especially informative. ${ }^{18}$ While this is a general problem in risk management, it is by far the most acute in operational risk.

\footnotetext{
${ }^{17}$ The figure was generated from actual operational risk loss data, a disguised client example for presentation here. The likelihood surface reflects relative probabilities that the lognormal severity parameters (mu, sigma) may have generated the observed data. The translation to capital includes an additional frequency assumption, one which as discussed is independent of severity, but that is common across the three points mapped. ${ }^{18}$ See Chernobai and Rachev (2006) and Opdyke and Cavallo (2012) for a discussion of robust statistics and operational risk modeling.
} 
To get a sense of what share operational risk consumes in the total regulatory capital pie, we collected published Pillar 3 disclosures and annual reports for 16 of the largest Basel II-compliant European, Australian, and Canadian banks that have begun disclosing AMA results since $2008 .{ }^{19}$ Note that data is not available for U.S. banks who have not yet fully implemented Basel II. The results show that from 2008 to 2012, regulatory capital requirements for operational risk have increased by about a third, both in terms of share of total capital (from an average of 9\% to 13\%) and dollar RWA (from \$559 to $\$ 737 \mathrm{BN})$. As it is well known that European regulators have been more amenable to use of expert judgment in capital modelling, our expectation is that when US reporting comes on-line, the percentage share of total capital accounted for by operational risk will be even higher given the much higher levels of liability in the U.S.

Figure 2: Operational risk capital growing by share and growing RWA

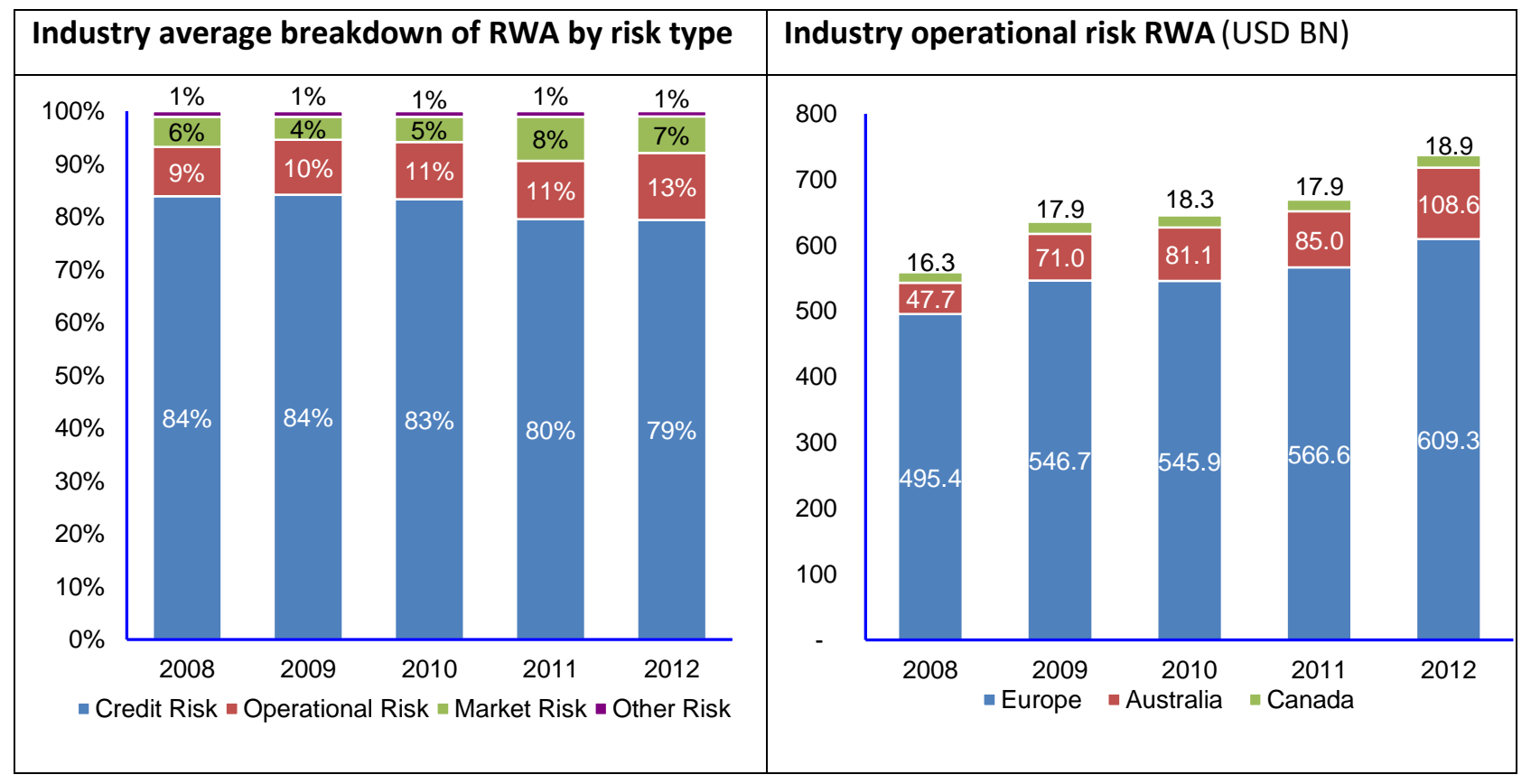

The question then becomes: how can an institution manage its exposure to operational risk? As we have indicated, better risk control (as reflected in BEICFs) will not appear to be rewarded in lower capital due to the concerns of U.S. regulators with subjectivity. What about mitigating risk through the purchase of insurance? Risk transfer or insurance is recognized in the Basel Accord as a mitigation method, subject to a ceiling of $20 \%$ of op risk capital. But as far as we know, at present no U.S. bank has

\footnotetext{
${ }^{19}$ The 16 banks are: Deutsche, BNP Paribas, Crédit Agricole, Barclays, Société Générale, UBS, ING Bank, UniCredit, Credit Suisse, Rabobank, Commerzbank, NAB, CBA, Westpac, ANZ, CIBC.
} 
yet successfully claimed any of this credit for regulatory capital relief. By contrast, several large European banks have successfully achieved capital relief from insurance. However, no European bank has come close to the $20 \%$ allowance; taken at face-value, if the mitigating impact of their insurance policies is less than $20 \%$ of operational risk capital the same would likely be true for large U.S. banks. Notwithstanding the desire of the insurance industry to improve its product to cover a greater share of banks operational risk exposure, this limitation largely makes moot any debate as to whether the credit for insurance should be increased to over $20 \%$.

There are a number of challenges with the use of insurance in this context. First is the difficultly in measuring (modelling) the extent of insurance's mitigating effect, a pre-condition for any bank's claim against capital. As mentioned, AMA models are generally constructed around the Basel event types, while insurance programs are built around discrete coverages. Unfortunately it turns out that the two taxonomies are incompatible with one another: in general any explicit map will show a many-to-many relationship between Basel event types and coverages. ${ }^{20}$ Apart from the modeling issue, there is also a legal question of needing to prove that insurance coverage, qualified by exclusions and language in covenants, may actually cover particular risks.

Use of historical data on insurance recoveries is also problematic. First it is rarely systematically captured; while the ORX data includes a field for "indirect recoveries" that are often insurance related, these recoveries are generally not identified in relational data to be linked to a particular insurance policy with specific terms and conditions of coverage, deductibles and limits purchased, all of which can change from year to year. Even date of recovery is rarely captured. Clearly this is an area fertile for significant improvement.

But perhaps the biggest concerns raised by regulators has to do with the "timeliness and certainty" of an insurance recovery. That is, how soon after a loss will there be a recovery, and recognizing that large losses are often contested by insurers, how certain can one be that there will even be a recovery? These are non-trivial concerns. Liquidity is real, often banks do not have luxury of delaying payment of (for example) restitution to customers or shareholders while waiting for an insurer to make good on its promise. On the other hand, the timing issue may be overrated if payouts do not need to be made promptly, or if deferred sufficiently would permit financing. On the certainty point, the insurance industry has not always done itself favors by (perceived as automatically) contesting claims that may fall into some sort of legal grey zone. It may be hoped that through better data capture over time that timeliness and certainty of insurance recoveries may be more carefully studied, and so credit for

\footnotetext{
${ }^{20}$ A notable exception is between the Basel event type Damage to Physical Assets (DPA) and property insurance.
} 
insurance's loss mitigating impact may be based on actual experience. Capital policy too should encourage this.

These quantitative challenges and performance concerns notwithstanding, the objectives of prudent risk management are furthered through the effective use of insurance; the reality is that banks continue to purchase insurance, regardless of (the lack of) regulatory recognition through reduction in operational risk capital. In this spirit, it would seem reasonable, perhaps as the regime evolves further, that regulators in the United States would follow the lead of Europe by offering some incentive to banks to continue and improve this important mechanism for risk mitigation.

\section{Policy Implications}

In general, we are skeptical of the efficacy of the current reliance on models for determining the capital of banks, and in particular the rigid translation from unstable and fragile models into regulatory capital requirements. Of the three risk types against which banks are required to hold regulatory capital - market, credit and operational risk - operational risk is hardest to measure and model, and the least well understood. It was the last risk type to be added to the regulatory capital calculation process, included only with Basel II in 2003. Market (i.e. trading) risk is by far the most precisely measured and modeled, and in that way the most tightly controlled. Kuritzkes and Schuermann (2010) place market risk at the most benign end of the spectrum of known, unknown and unknowable risks, typically making up only around $6 \%$ of total risk in a bank (though more in some, of course).

Yet even this risk type is hard to pin down precisely. Recently the Basel Committee asked 15 banks to calculate regulatory market risk capital for a set of hypothetical portfolios (BCBS 2013), with resulting wide variation. The difference between the smallest and largest was two to three-fold, depending on the portfolio. If the variation in computed regulatory capital for the risk that is best understood, best measured and subject to the least model controversy is so wide, it should make us especially cautious about hard-wiring model output directly to required capital. Indeed Kuritzkes and Scott (2005) show this difference for operational risk capital to be on the order of ten-fold, and Kuritzkes (2006) reports up to a twenty to one range of implied operational risk capital.

So what could we do about operational risk? On consideration of a number of alternatives we offer four recommendations.

1. Address model fragility. Improve upon the existing LDA framework in at least two directions that are not mutually exclusive. 
a. First, reduce overall estimation noise and sensitivity of models to incoming event arrivals by anchoring key severity parameters. Through industry aggregate data, regulators have access to a broader experience base than any individual bank. There are good reasons to believe that within an event type, the experience across banks should reflect some commonality. While this may not be true for some high-frequency low-severity event types as execution and delivery process management (EDPM) where specific product mix is critical, it is arguably more appropriate for the low-frequency high-severity event types as CPBP where the banks shares a more common exposure say to litigation. For these event types, regulators could specify certain parameters, such as the type of distribution and the shape parameter (exponent) that defines tail density, i.e., the degree to which fat tails dominate severity. Importantly, this parameter is highly sensitive to "the next" large operational risk event, as illustrated above largely responsible for step changes seen in required capital. As fat tails mean greater fragility, removing this degree of freedom would tend to lend stability to the otherwise highly sensitive models. This would also significantly decrease bank's dependence on volatile external data. In this case, it would still be the responsibility of banks to scale the distributions to their operations, and to determine appropriate frequency assumptions.

As the experience base broadens and lengthens, regulators could update these shape parameters (different ones for different event types) in a way that balances the information value that one bank's experience has for all banks without going to the current extreme where, potentially, every bank has to self-insure, with capital, against operational risk events from any bank. This approach should go a long way towards addressing the commons problem that disincentivizes banks to use consortium data.

b. Lower the computed confidence interval to reduce the estimation sensitivity that invariably comes with extrapolations into a very fat tail. An estimate that is less far out in the tail - say $95 \%$ instead of $99.9 \%$ - could then be scaled up, recognizing that estimates of the $99.9 \%$ tail are much (!) noisier than, say, 95\%. This approach follows the methodology for computing market risk capital where the chosen computed percentile is $99 \%$, and is then scaled up by a regulatory-prescribed multiple of 3-4X. Since market risk is the best measured and most accurately modeled of the three risk types, the estimated confidence level for operational risk ought to be lower. However, to be effective, one would first need to gain assurance that 
lowering the estimated confidence interval to, say, $95 \%$ in fact reduces the estimation noise which plagues the fat tail.

c. Reconsider the Standardized Approach, an approach offered under Basel II for computing regulatory capital that does not rely on bank-internal models, and make that approach, as further refined, optionally available to large banks (as Basel itself permits). This may be thought of as a logical extension to anchoring certain parameters of an internal model (as suggested above) but where regulators anchor all parameters. While this recommendation would appear to contradict the goal that capital requirements be a sensitive and accurate reflection of each bank's unique risk profile, many will argue that the goal is really a chimera - that "accuracy" in the context of operational risk is just not possible. Indeed, recent experience with models of operational risk and the fragility issues discussed in this paper would tend to support this view. While the idea that the level of a bank's operations is reasonably proxied by income in different business lines is debatable, this more simple approach successfully avoids the problem of the fragile fitting of distributions to past events. If the supervisors believe that the percentages proposed in the Standardized Approach, or the definitions of the business lines to which they apply are not accurate or sufficient to reflect operational risks faced by banks, they could revise these parameters.

2. Relax the current tight link between model output and required (regulatory) capital. Given the fragility of the statistical models, having a very tight coupling between model output and capital hardly seems desirable for either regulator or regulated. There are a few possible ways of making progress here:

a. Stronger role for scenario analysis. Moving away from models, we support the use of scenario analysis as a formal mechanism to incorporate expert judgment. European regulators, being much more skeptical of the use of unstable statistical models to determine regulatory capital, have already gone down this path. We recognize the incentive problem raised by the regulators: banks have a strong incentive to make only downward adjustments to required regulatory capital. But the current approach, namely that expert judgment can only be used to increase required capital from model output, seems unproductively asymmetric.

b. We hold a similar view toward the use of business environment and internal control factors BEICFs). Given that the goals of risk management are to reduce the probability of loss 
occurrence and mitigate severity, further investment into more sophisticated approaches to BEICFs would appear to be of primary importance. As these methods grow more accurate, and observable metrics by which risk may be measured become better understood, BEICFs would naturally have a role in modelling. We note the close relationship between the (unobservable) control environment and the (observed) loss history. Through more sophisticated use of BEICFs, some institutions have narrowed the often-seen gulf between operational risk measurement and operational risk management.

c. Model averaging. If there is reluctance to loosen the link between an LDA model's output and required capital, one could mitigate the impact of any one fragile model by averaging across several competing models, built on complimentary information sets. There is a welldeveloped statistical literature on model averaging as a way of achieving robustness; for an excellent survey, see Timmermann (2006). Indeed it seems that the Federal Reserve, in their modeling of operational risk in the CCAR program, made use of three alternative approaches in arriving at their own estimate of operational risk impact in the stress test. ${ }^{21}$

3. Work with the banking industry, as have European regulators, to provide at least some capital relief for insurance, particularly given the rather modest percentage of insurance coverage for operational risk. We would expect this to have the dual effect of incentivizing banks to make better use of risk transfer as means of active risk management, and second to encourage the insurance industry to improve its product, possibly expanding coverage to areas of operational risk currently not covered, and improving terms and conditions that "timeliness and certainty" concerns are reduced. Linked with this recommendation is the next, where data identifying timing of insurance recoveries, and referencing particular insurance policies under which recoveries are made, will be key to track the effectiveness of insurance as mitigating risk.

4. Revisit / expand upon the Basel II operational risk event type taxonomy. It has been more than a decade since the existing taxonomy was designed, leading toward the Basel II Accord. Banks have spent this decade building up their internal databases, and vendors have in turn collected and harmonized public and private member data. But as described above, while the industry has accumulated many observations classified by event type and business line, the data remain largely opaque, difficult to assess for relevance, difficult to use for modelling and not so helpful when it

${ }^{21}$ See http://www.federalreserve.gov/newsevents/press/bcreg/dfast 2013 results 20130314.pdf. 
comes to learning from other institutions' experience. Our recommendation is not that the current taxonomy be thrown out, but rather complemented by additional field specifications as product type, litigated vs. not-litigated liability, more detailed data on type and timing of recoveries (including insurance described above), and others that could be further exploited though modelling the factors that would better explain loss. Many, perhaps all, institutions collect a variety of variables in addition to those required by regulation and the data consortia. However, there is little by way of standardization beyond Basel's event types and business lines. We suggest more systematic standardization for new variables that will progress the science of operational risk management, ideally including variables that could be aggregated and shared broadly, with the regulators and with other institutions through the data consortia. This would provide clear benefits for statistical modeling of operational risk, and not getting this right has profound knock-on effects to risk management. Given its importance, special attention should be given to assigning a separate category to liability risk.

To explore the efficacy of the recommendations above, if data are not currently in-hand the US regulators may wish to conduct a broad operational risk data gathering exercise. Subsequent analyses could include exploring the impact on model stability through fixing parameters, lowering confidence bounds, and on an enhanced/expanded taxonomy. The Federal Reserve, through its data gathering efforts in the CCAR program, by now has a very rich database of operational risk information and should thus also be in a good position to conduct such analysis. If the regulatory community finds that even with the largest operational risk database available, with a re-optimized event type taxonomy, with fixed parameters or lower confidence intervals, that the resulting models are still quite unstable, it would call into question the existing regulatory strategy even more profoundly. We think that data gathering, analysis and directed research should be rather uncontroversial. The time seems ripe for conducting such an exercise, especially as the industry has experienced a devastating financial crisis, generating more data and an appetite for reconsidering risk and capital approaches.

Meanwhile we strongly encourage taking some steps towards relaxing the current tight link between model output and required (regulatory) capital, perhaps by starting with allowing model averaging to directly address the fragility point. This step we think should also be quite uncontroversial. Further steps can be taken as we learn more. Until our understanding of operational risks increases, required regulatory capital should be based on methodologies that are simpler, more standardized, more stable and more robust. 
Table 1. Basel Loss Event Type Classification*

\begin{tabular}{|c|c|c|}
\hline \multicolumn{2}{|c|}{ Event-Type Category (Level 1) } & Category (Level 2) \\
\hline IF & Internal fraud & $\begin{array}{l}\text { - Unauthorized Activity } \\
\text { - Theft and Fraud }\end{array}$ \\
\hline $\mathrm{EF}$ & External fraud & $\begin{array}{ll}\text { - } & \text { Theft and Fraud } \\
\text { - } & \text { Systems Security }\end{array}$ \\
\hline EPWS & $\begin{array}{l}\text { Employment Practices and Workplace } \\
\text { Safety }\end{array}$ & $\begin{array}{ll}\text { - } & \text { Employee Relations } \\
\text { - } & \text { Safe Environment } \\
\text { - } & \text { Diversity and Discrimination } \\
\end{array}$ \\
\hline СРBP & Clients, Products \& Business Practices & $\begin{array}{ll}\text { - } & \text { Suitability, Disclosure and Fiduciary } \\
\text { - } & \text { Improper Business or Market Practices } \\
\text { - } & \text { Product Flaws } \\
\text { - } & \text { Selection, Sponsorship and Exposure } \\
\text { - } & \text { Advisory Activities }\end{array}$ \\
\hline DPA & Damage to Physical Assets & - $\quad$ Disasters and other events \\
\hline BDSF & Business Disruption and System Failures & - $\quad$ Systems \\
\hline EDPM & $\begin{array}{l}\text { Execution, Delivery and Process } \\
\text { Management }\end{array}$ & $\begin{array}{l}\text { - } \text { Transaction Capture, Execution and Maintenance } \\
\text { - } \text { Monitoring and Reporting } \\
\text { - } \text { Customer Intake and Documentation } \\
\text { - } \quad \text { Trade Counterparties } \\
\text { - Vendors and Suppliers }\end{array}$ \\
\hline
\end{tabular}

* Basel Committee on Banking Supervision, A Revised Framework, Annex 7, June 2004. 
Table 2. Basel Mapping of Business Lines*

\begin{tabular}{|c|c|}
\hline Business Line (Level 1) & Business Line (Level 2) \\
\hline Corporate Finance & $\begin{array}{ll}\text { - } & \text { Corporate Finance } \\
\text { - } & \text { Municipal/Government } \\
\text { - } & \text { Finance } \\
\text { - } & \text { Merchant Banking } \\
\text { - } & \text { Advisory Services }\end{array}$ \\
\hline Trading and Sales & $\begin{array}{ll}\text { - } & \text { Sales } \\
\text { - } & \text { Market Making } \\
\text { - } & \text { Proprietary Positions } \\
\text { - } & \text { Treasury }\end{array}$ \\
\hline Retail Banking & $\begin{array}{ll}\text { - } & \text { Retail Banking } \\
\text { - } & \text { Private Banking } \\
\text { - } & \text { Card Services }\end{array}$ \\
\hline Commercial Banking & - Commercial Banking \\
\hline Payment and Settlement & - $\quad$ External Clients \\
\hline Agency Services & $\begin{array}{ll}\text { - } & \text { Custody } \\
\text { - } & \text { Corporate Agency } \\
\text { - } & \text { Corporate Trust }\end{array}$ \\
\hline Asset Management & $\begin{array}{l}\text { - Discretionary Fund Management } \\
\text { - } \quad \text { Non-Discretionary Fund Management }\end{array}$ \\
\hline Retail Brokerage & - $\quad$ Retail Brokerage \\
\hline
\end{tabular}




\section{References}

Basel Committee on Banking Supervision, 2006, "International Convergence of Capital Measurement and Capital Standards: A Revised Framework," available at http://www.bis.org/publ/bcbs128.htm, June.

, 2013, "Regulatory consistency assessment programme (RCAP) - Analysis of risk-weighted assets for market risk," available at http://www.bis.org/publ/bcbs240.pdf

Board of Governors of the Federal Reserve System, 2011. "Interagency Guidance on the Advanced Measurement Approaches for Operational Risk." Available at http://www.federalreserve.gov/bankinforeg/srletters/sr1108a1.pdf

Chernobai, Anna and Svetlozar T. Rachev, 2006, "Applying Robust Methods to Operational RiskModeling." Journal of Operational Risk 1:1, 27-41.

Chernobai, Anna and Yildiray Yildirim, 2008, "The Dynamics of Operational Loss Clustering." Journal of Banking \& Finance 32, 2655-2666.

Chernobai, Anna, Philippe Jorion and Fan Yu, 2011, "The Determinants of Operational Risk in US Financial Institutions." Journal of Financial and Quantitative Analysis 46:6, 1683-1725.

Kuritzkes, Andrew P. and Hal S. Scott, 2005, "Sizing Operational Risk and the Effect of Insurance: Implications for the Basel II Capital Accord." Ch. 7 in Hal Scott (ed.) Capital Adequacy Beyond Basel: Banking, Securities, and Insurance, Oxford, UK: Oxford University Press.

Kuritzkes, Andrew P., 2006, Comment on Patrick de Fontnouvelle, Eric S. Rosengren and John S. Jordan, 'Implications of Alternative Operational Risk Modeling Techniques,' in Mark Carey and Rene M. Stulz, The Risks of Financial Institutions, University of Chicago Press.

Kuritzkes, Andrew P. and Til Schuermann, 2010, "What We Know, Don't Know and Can't Know about Bank Risk: A View from the Trenches," ch. 6 in Francis X. Diebold, Neil Doherty and Richard J. Herring (eds.), The Known, The Unknown and The Unknowable in Financial Risk Management, Princeton University Press.

Moosa, Imad, 2011, "Operational risk as a function of the state of the economy." Economic Modelling $28,2137-2142$.

Opdyke, John D. and Alexander Cavallo, 2012, "Estimating Operational Risk Capital: The Challenges of Truncation, the Hazards of Maximum Likelihood Estimation, and the Promise of Robust Statistics." Journal of Operational Risk 7:3, 3-90.

Rosenberg, Joshua V. and Til Schuermann, 2006, "A General Approach to Integrated Risk Management with Skewed, Fat-tailed Risks." Journal of Financial Economics 79:3, 569-614.

Sekeris, Evan G., 2012, "New Frontiers in the Regulatory Advanced Measurement Approach." Ch. 2 in Ellen Davis Operational Risk: New Frontiers Explored. London: Risk Books.

Timmermann, A., 2006, Forecast Combinations. In Graham Elliott, Clive W.J. Granger andAllan Timmermann (eds.), Handbook of Economic Forecasting. Elsevier, 135-196. 